
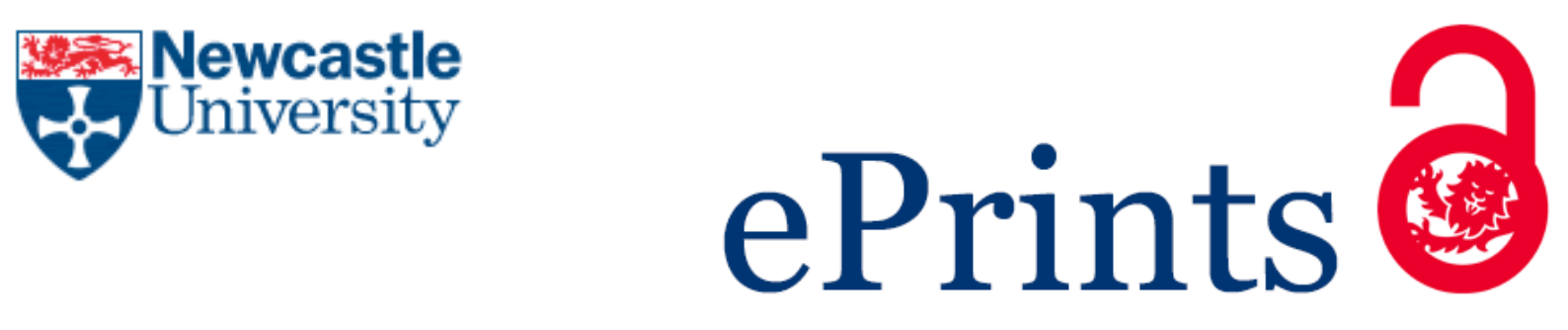

Elamin MEMO, James DA, Holmes P, Jackson G, Thompson JP, Sandilands EA, Bradberry S, Thomas SHL.

$\underline{\text { Reductions in emergency department visits after primary healthcare use of }}$ the UK National Poisons Information Service.

Clinical Toxicology 2017,

https://doi.org/10.1080/15563650.2017.1390120

\title{
Copyright:
}

This is an Accepted Manuscript of an article published by Taylor \& Francis in Clinical Toxicology on 26/10/2017, available online: http://dx.doi.org/10.1080/15563650.2017.1390120.

DOI link to article:

https://doi.org/10.1080/15563650.2017.1390120

Date deposited:

$10 / 10 / 2017$

Embargo release date:

26 October 2018

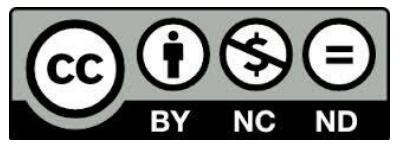

This work is licensed under a

Creative Commons Attribution-NonCommercial-NoDerivatives 4.0 International licence 


\section{Reductions in Emergency Department Visits after primary healthcare use of the UK National Poisons Information Service.}

Elamin Muhammad EMO, ${ }^{1}$ James David $A,{ }^{1}$ Holmes Peter, ${ }^{1}$ Jackson Gillian, ${ }^{2}$ Thompson John P, ${ }^{3}$ Sandilands Euan A, ${ }^{2}$ Bradberry Sally, ${ }^{4}$ Thomas Simon HL. ${ }^{1,5}$

${ }^{1}$ National Poisons Information Service (Newcastle Unit), Regional Drug and Therapeutics Centre, Newcastle upon Tyne Hospitals NHS Foundation Trust, Newcastle, UK

${ }^{2}$ National Poisons Information Service (Edinburgh Unit), Royal Infirmary, Edinburgh, UK

${ }^{3}$ National Poisons Information Service (Cardiff Unit), University Hospital Llandough, Cardiff, UK

${ }^{4}$ National Poisons Information Service (Birmingham Unit), City Hospital, Birmingham, UK

${ }^{5}$ Medical Toxicology Centre, Institute of Cellular Medicine, Newcastle University, Newcastle, UK

Keywords poisoning, hospital presentations, emergency departments 


\section{Abstract}

Background: Suspected poisoning is a common cause of hospital admission internationally. In the United Kingdom, the National Poisons Information Service (NPIS), a network of four poisons units, provides specialist advice to health professionals on the management of poisoning by telephone and via its online poisoning information and management database, TOXBASE®.

Objective: To demonstrate the impact of NPIS telephone advice and TOXBASE® guidance on poisoning-related referrals to emergency departments (ED) from primary health care settings.

Methods: A telephone survey of primary healthcare providers calling the NPIS and an online survey of TOXBASE® primary care users were conducted to evaluate the effect of these services on poisoning related ED referrals. Enquirers were asked to indicate whether referral was needed before and after using these information sources. 
Results: The number of cases considered by enquirers appropriate for ED referral was reduced from $1178(58.1 \%)$ before to $819(40.4 \%)$ after provision of telephone advice for 2028 cases (absolute reduction 17.7\%, 95\% CI 14.6, 20.7\%) and from 410 (48.2\%) before to $341(40.1 \%)$ after consideration of TOXBASE® guidance for 851 cases (absolute reduction $8.1 \%, 95 \%$ CI 3.3, 12.9\%). By extrapolating these figures over a full year, it is estimated that these services prevent approximately 41,000 ED referrals annually.

Conclusions: The use of NPIS services significantly reduced ED referrals from primary healthcare services with resulting avoided healthcare costs exceeding the current annual NPIS budget. Further studies are needed to evaluate other potential benefits of accessing NPIS services.

242 words 


\section{Introduction:}

Poisoning, actual or suspected, is common. In the United Kingdom (UK) there are more than 170,000 poisoning-related hospital admissions annually [1], contributing approximately $1 \%$ of all hospital admissions [2,3]. Hospital admissions and deaths related to poisoning and drug abuse have increased over the last decade [4,5]. Suspected poisoning therefore presents a considerable workload for primary and secondary care.

In the UK, the National Poisons Information Service (NPIS), a network of 4 poisons units, provides information and evidence-based management advice about poisoning to health professionals. This is available via the online toxicology database, TOXBASE®, the related TOXBASE® app for mobile devices [6] and a 24-hour telephone advice service staffed by trained Specialists in Poisons Information (SPIs) supported by an on-call rotation of consultant clinical toxicologists. The NPIS aims to provide the required expertise to avoid unnecessary hospital referrals and admissions for patients at low risk of harm, while improving the quality of treatment and shortening hospital stay for those at risk of clinical toxicity [1]. The NPIS is commissioned by Public Health England (PHE) on behalf of all UK Health Departments. 
Common users of the telephone enquiry service and of TOXBASE® include hospitals, particularly ED, and primary healthcare organisations including general practitioners (GPs), walk-in health centres, ambulance services, prison staff and public access healthcare telephone advice services (NHS 111 in England [7], NHS Direct in Wales [8] and NHS 24 in Scotland [9]). The NPIS received approximately 48,000 telephone enquiries in the 2015/16 fiscal year (April to March). Over the same period, the NPIS online database TOXBASE® registered nearly 609,000 user sessions and 1.69 million separate page views of TOXBASE® entries [1].

Studies done in other countries have demonstrated the cost-effectiveness of poisons centres, but such studies have not previously been conducted in the UK. One of the major potential benefits of poisons centres is that the advice they provide may allow some patients who would otherwise be referred to an ED to be treated at home. This improves the quality and convenience of care for patients and also reduces healthcare costs. This study was therefore performed to determine the impact of NPIS telephone and TOXBASE® advice on rates of ED referral after enquiries from primary care and to estimate the cost impact of the advice provided. 


\section{Methods:}

This study was performed as a service evaluation and as such approval from a research ethics committee is not required in the United Kingdom.

\section{Telephone survey:}

All four NPIS units participated in a prospective telephone survey, although they did not all start on the same date due to different on call allocations and requirements for local preparation. The NPIS units in Newcastle upon Tyne and Cardiff started data collection on $4^{\text {th }}$ January 2016 and those in Edinburgh and Birmingham on $13^{\text {th }}$ January and $20^{\text {th }}$ January 2016 respectively. All four NPIS units completed data collection at midnight on $19^{\text {th }}$ February 2016 so units collected data over 31 to 47 days.

Callers to the NPIS telephone advice line from NHS primary healthcare professionals treating or managing a patient with confirmed or suspected exposure to poisoning were invited to participate. This involved a two-question telephone survey to determine patient management in the absence of the NPIS advice service and changes in the proposed management following consulting the service. Calls from hospitals (secondary care settings), the Republic of Ireland, or those that did not relate to management of a specific patient were excluded. 
Enquirers were asked to choose their planned course of management prior to receiving NPIS telephone advice or reading TOXBASE®. After receiving the relevant NPIS advice or reading TOXBASE®, the enquirers were asked again to choose their planned course of management. Referral options were: (1) Attend a Hospital ED; (2) Refer to a General Practitioner (GP); (3) Refer to a pharmacy or (4) home observations only. The text of the script used by the SPI is provided in the on-line supplementary material

The survey was conducted by NPIS SPIs and responses were entered into the free comments section of the online UK Poisons Information Database (UKPID) database using unique codes with capitalised letters. These were later extracted onto a Microsoft Excel® spreadsheet from which the total number of registered responses and breakdown of these responses were analysed.

Incomplete, unclear or inaccurate responses were identified and reviewed by a physician and an experienced SPI. Recorded responses determined to have clear information indicating the observed outcomes were accepted. The total number of eligible calls to for inclusion into the study was extracted by reviewing UKPID. 


\section{TOXBASE® survey:}

During the period $9^{\text {th }}$ May to $14^{\text {th }}$ June 2016 , TOXBASE® users from primary healthcare services were invited to participate in a two-question survey via a pop-up box, which appeared to primary care but not secondary care users accessing a product page. Users were asked to choose their planned course of management prior to and again after accessing TOXBASE® advice and information. The same referral options were used as in the telephone survey. Text used in the pop-up box is provided in the supplementary material.

The extracted results were transferred onto a Microsoft Excel® spreadsheet, which was analysed to assess completed responses.

\section{Data analysis}

Statistical significance was assessed by calculating percentage absolute changes in referrals to each referral option and the respective $95 \%$ confidence intervals after use of the telephone service or TOXBASE. Differences in proportions of patients referred before and after use of these services was also compared by chi square testing using the Yates continuity correction, with $\mathrm{P}<0.05$ considered statistically significant.

To calculate potential cost savings made from avoided ED attendances, the 2014-2015 UK National Health Service (NHS) reference cost of $£ 156.64$ for a typical poisoning related ED 
attendance (HRG4 code VB08Z) [10-13] was used. The lowest cost tariff from the 2015 UK General Practitioner Unit Costs [14] was used to calculate potential cost savings from avoided GP referrals.

The total number of avoided patient referrals was extrapolated based on the number of patient specific telephone enquiries received by the NPIS during the 2015/16 financial year.

\section{Sensitivity analyses}

Sensitivity analyses were conducted of the NPIS telephone survey data by classifying Enquiries according to time received and PSS of enquiry. These subgroups were compared to identify potential differences or bias in recorded referral plans related to timing or PSS of enquiry.

Extrapolated annual referral figures were calculated based on the numbers of NPIS telephone enquiries received during the 2015/16 financial year as registered on UKPID and classified according to time received and PSS.

\section{Results:}


There were 3916 telephone enquiries meeting the study inclusion criteria, but 152 callers (3.9\%) declined to participate, 140 cases $(3.6 \%)$ had incorrectly or ambiguously coded responses and $1596(40.8 \%)$ enquirers were not asked the two study questions, usually because of concurrent pressures on service provision. Therefore, 2028 completed responses were recorded (Figure 1 and Table 1). The largest group taking part in the survey were staff of publically accessible health advice telephone lines (e.g. NHS 111), but general practitioners and ambulance service staff were also commonly involved (Table 1).

[Table 1 near here]

Of all completed responses, $962(47.4 \%)$ and 829 (40.9\%) concerned patients under the age of 16 and 6 years of age respectively. There were 994 (49\%) responses related to enquiries made outside normal office hours, of which $456(45.9 \%)$ related to children aged 0 to 16 years.

In the absence of the NPIS telephone advice service, callers reported that they would have referred $1178(58.1 \%)$ of the 2028 patients to an ED. Other planned referral routes included to a general practitioner $(515,25.4 \%)$ or a pharmacy $(59,2.9 \%)$, while home observations were considered appropriate for $276(13.6 \%)$ patients (Table 2). Following NPIS telephone advice, changes in planned management included a reduction in ED $(17.7 \%, 95 \%$ CI 14.6- 
20.7), GP (15.3\%, 95\% CI 12.9-17.6) and pharmacy (2.6\%, 95\% CI 1.8-3.5) referrals (Table

2). These overall figures are net changes incorporating a smaller number of cases where NPIS advice lead to upgrading of the planned referral, e.g. 119 patients referred to an ED rather than a GP and 55 patients referred to an ED and 12 to a GP instead of for home care. (Table 2)

[Table 2 near here]

During the 2015/16 financial year, 46,885 patient specific telephone enquiries were received by the NPIS, including 33,859 from primary care. Extrapolating the changes described here in intended referral routes across a whole year suggests that provision of NPIS telephone advice avoids almost 6,000 ED visits and 8,600 GP referrals. Based on the 2014-2015 NHS reference cost of $£ 156.64$, NPIS telephone advice to primary care users provided an estimated saving of $£ 939,000$ annually in terms of net reductions in ED attendances. Using the lowest cost tariff, GP referrals avoided as a result of NPIS telephone advice are estimated to save approximately $£ 228,000$ annually in addition.

These estimates, however, assume that the proportion of ED visits avoided was not affected by the severity of poisoning or the time of day of the enquiry, but there were differences in these characteristics between calls with and without recorded survey responses. Calls with 
recorded survey responses had a reduced proportion received outside normal office hours (994/2028 [49.1\%] vs. 900/1596 [56.5\%], difference 7.4\% [95\% CI: 4.1-10.7]), a higher proportion with a Poison Severity Score (PSS) of 0 (no symptoms) [15] (1556/2028 [76.7\%] vs $1148 / 1596$ [69.2\%], difference $4.8 \%$ [95\% CI 1.9-7.7]) and a lower proportion with a PSS of 1 (minor symptoms) (418/2028 [20.6\%] vs 375/1596 [23.5\%], difference $2.8 \%$ [95\% CI 1.3-5.7]). ED referral was avoided in a higher proportion of enquiries received during normal office hours and when the PSS was 0 or unclassified (Table 3). As these are circumstances when survey responses were more likely to be received, the overall savings in ED visits and costs described above will be overestimated. To correct for this, separate estimates were performed for each of 4 groups and these were then summed (Table 3). This reduced the annual number of estimated ED referrals avoided from 5994 to 5643 and the estimated EDrelated cost saving from $£ 939,000$ to $£ 884,000$.

[Table 3 near here]

\section{TOXBASE® Survey:}

During the period of study, 31,151 TOXBASE® page loads from primary healthcare users were registered, but survey questions were answered for only 851 (2.7\%) of these.

In the absence of TOXBASE® advice, 410 respondents (48.2\%) would have referred the patient to an ED, 175 to a GP (20.6\%) and 19 to a Pharmacy (2.2\%), with 247 respondents 
opting for home care (29\%). Following use of TOXBASE®, cases considered appropriate for ED referral reduced to 341 , an absolute reduction of $8.1 \%$ (95\% CI 3.3, 12.9). Use of TOXBASE® did not significantly affect GP (absolute reduction 1.8\%, 95\% CI -2.1, 5.6) or pharmacy $(0.7 \%, 95 \%$ CI $-0.7,2.2)$ referrals, although a significant increase in patients considered suitable for home care was observed $(10.6 \%, 95 \%$ CI 6, 15). As in the telephone survey, the figures also incorporate those cases where access to TOXBASE® led to upgrading of the planned referral (Table 4).

[Table 4 near here]

The numbers of TOXBASE® accesses from primary healthcare services and users during the 2016/17 financial year was 427,568. From this figure, the net annual number of avoided ED referrals is estimated as 34,600. Based on NHS reference costs, this translates into an estimated annual saving of approximately £5.4M. 


\section{Discussion:}

These surveys involving primary care users of NPIS telephone advice and TOXBASE® suggest that provision of NPIS advice substantially reduces ED referrals of patients assessed in primary care for suspected or confirmed poisoning and increases the numbers of those considered suitable for home care. NPIS telephone advice also reduced referrals to general practitioners and pharmacies, although reductions were not statistically significant for TOXBASE®. Many of these referrals related to children or occurred outside normal office hours, circumstances when the avoidance of unnecessary referral is especially important.

The cost effectiveness of poisons centres and the impact of the telephone advice they provide on emergency admissions has been reported previously, for example in studies performed in the USA and Singapore [15-21]. In these countries, enquiries are taken from the general public as well as health professionals so the impact cannot necessarily be extrapolated to services where enquiries are only accepted from health professionals, such as in the UK. We are not aware of previous research studying the impact of health-professional only services on ED referral patterns. The research presented here, however, demonstrates that use of the NPIS telephone advice service in the UK by health professionals prevents many potentially unnecessary hospital referrals to $\mathrm{ED}$ and general practitioners. 
In the UK, health professionals can also obtain advice on managing patients with suspected poisoning by accessing the NPIS on-line poisons database TOXBASE®. This route is now used substantially more often than the telephone advice facility. To get an accurate assessment of the impact of the NPIS it is therefore essential to study the impact of TOXBASE® on referral patterns. The data presented here also demonstrates a potential reduction in referral intentions after use of this resource. Although the reduction was smaller in relative terms, the numbers of ED referrals estimated to be avoided was much larger because of the substantially larger numbers of enquiries made via this route than by telephone. The proportion of ED referrals avoided was higher after use of the telephone service rather than TOXBASE. This may reflect the value of input from a trained specialist in poisons information with specific information about the case being referred, as opposed to interpretation of text on TOXBASE written to cover all potential scenarios by less experienced health professionals.

The net effect from use of NPIS telephone and TOXBASE® services is a considerable reduction in ED referrals, as well as smaller reductions in referrals to general practitioners or pharmacies. There are considerable benefits to patients, especially children, from avoiding unnecessary and potentially distressing referrals, especially as these are likely to result in unnecessary examinations, investigations and worry. The potential financial savings are also considerable; using conservative tariff costs and ignoring other associated costs (transport to 
hospital etc.), the estimated financial saving from these reduced referral numbers was approximately $£ 6.4 \mathrm{M}$, which exceeds the overall NPIS budget, currently approximately $£ 3.5 \mathrm{M}$. These savings relate to hospital costs and do not take into account other savings from reduced ED referrals, such as ambulance costs or time away from work for carers. Furthermore, this analysis does not take account of many other potential cost-benefits of the NPIS which were not evaluated in this research. Examples include possible reductions in admission after ED attendance, improved quality of care resulting in better clinical outcomes, shortened hospital stay in those admitted and reduced loss of earnings from time off work.

\section{Limitations and strengths}

The most important limitation is the incomplete response rate obtained in both the telephone and especially the TOXBASE® study, raising the possibility that those who responded to the survey might not reflect the overall population of service users. The incomplete telephone survey is not unexpected as it is very challenging for poisons centre staff to administer surveys at times of high demand; a similar US poison centre survey conducted on posttelephone consultation basis had a survey completion rate of $47.1 \%$ [22].

In our study, there were small differences in the characteristics of calls with and without recorded survey responses, with the former being more likely to occur during normal office 
hours and to concern a patient with a PSS of 0 (no symptoms). These are subgroups where referral to an ED is less likely to be necessary, so the study may overestimate the total numbers of ED referrals avoided. We were able to correct for that by calculating savings separately for each subgroup; this made only a small difference to the estimated savings. We cannot exclude the possibility that other biases might arise from the incomplete data collection.

The very low response to the on-line service evaluation mirrors other studies using this platform $[23,24]$. Improving response rates is difficult because it would be inappropriate to prevent users from bypassing the survey questions to get to the information they need. No patient data are required to access TOXBASE®, so it is not possible to compare patient characteristics between those where the study questions were or were not answered. The possibility of bias introduced by the low response rate cannot therefore be excluded. We can say, however, that the proportion of TOXBASE® accesses during normal office hours in our study $(32 \%)$ is not substantially different from the proportion of registered TOXBASE® accesses during normal office hours for the 2016-17 fiscal year (31\%).

The TOXBASE® survey numbers reported are not strict patient numbers or specific logins but page load counts. Therefore, a user may potentially generate a duplicate count if the page has been refreshed or reviewed more than once. A single user may need to access more than one product page for multiple agent exposures and this might result in an overestimation of the numbers of patients involved. However, it is more likely that the majority of such 
presentations are referred for further review or hospital admission, especially as general guidance recommends referral for multiple agent exposures. As the study survey was conducted using a simple "no extra cost" IT platform, the amount of specific and detailed information that could be collected was limited.

The telephone survey was conducted by NPIS SPIs, thus there is a risk of recording and researcher bias. However, a major effect seems unlikely as the callers surveyed were not aware of the primary hypothesis of the study and the telephone advice provided by the SPIs is standardised and governed by evidence-based guidelines. In support of unbiased reporting, the referral intent was upgraded for a number of referrals, e.g. to ED referral rather than home observation. The possibility of acquiescence bias, where respondents might answer the $2^{\text {nd }}$ survey question in a manner that would be exactly the same as NPIS advice should also be considered, particularly if in favour of avoiding a hospital admission. However, the wording of the survey was designed to avoid exposing the aims of the study to the callers. Callers were advised that the SPIs were undertaking a service evaluation exercise for the NPIS and that this was not an assessment of their performance, management or the service they represented. Likewise the order of the 4 answers with the most expensive /intensive option mentioned first, rather than the target outcome, helped prevent any response order bias; although there is a potential for question order bias because of the flow of the 2 questions. 
This study also has a number of strengths. Both NPIS telephone and TOXBASE® surveys were carried out in a prospective manner and in real time and real world conditions. Telephone enquiries meeting the study inclusion criteria were similar in characteristics to NPIS enquiries overall. Engagement of callers with the telephone survey was not problematic, with only $6.6 \%$ of eligible callers $(152 / 2320)$ declining to participate. In addition, the number of entries that were excluded due to inaccurate or incomplete records was only $6 \%(140 / 2320)$.

\section{Conclusions:}

The use of NPIS services significantly reduced ED referrals from primary healthcare services. The estimated resulting savings from this alone exceed the current total NPIS budget, demonstrating the cost-effectiveness of the service. Further studies are needed to evaluate other benefits, such as improvements in quality of care, reductions in morbidity, mortality or hospital inpatient stay and avoidance of hospital admission in those referred to the ED, referral to other health services and productivity loss related to unnecessary health care.

3242 words 


\section{References:}

[1]- National Poisons Information Service. NPIS Annual Report 2015/16. Centre for Radiation, Chemical and Environmental Hazards. Public Health England. [Online] Available at: http://www.npis.org/NPISAnnualReport2015-16.pdf (Accessed: 23 December 2016).

[2]- NHS Confederation. Key Statistics on the NHS .May 2016. [Online] Available at: http://www.nhsconfed.org/resources/key-statistics-on-the-nhs (Accessed: 8 August 2016).

[3]- National Poisons Information Service. NPIS Annual Report 2014/15. Centre for Radiation, Chemical and Environmental Hazards. Public Health England. [Online] Available at: http://www.npis.org/NPISAnnualReport2014-15.pdf (Accessed: 31 March 2016).

[4]- Health and Social Care Information Centre (HSCIC).2016. Statistics on Drug Misuse, England 2016. [Online] Available at: http://digital.nhs.uk/catalogue/PUB21159/drugmisu-eng-2016-rep.pdf (Accessed: 7 September 2016). 
[5]- Office for National Statistics. 2015. Deaths Related to Drug Poisoning in England and Wales: 2014 registrations. [Online] Available at:

http://www.ons.gov.uk/peoplepopulationandcommunity/birthsdeathsandmarriages/deaths /bulletins/deathsrelatedtodrugpoisoninginenglandandwales/2015-09-03 (Accessed: 7 September 2016).

[6]- TOXBASE® website. [Online] Available at: http://www.toxbase.org/About-the-NPIS--TOXBASE (Accessed: 3 April 2016).

[7]- NHS Choices. NHS 111 Service. 2015. [Online]. Available at: http://www.nhs.uk/NHSEngland/AboutNHSservices/Emergencyandurgentcareservices/P ages/NHS-111.aspx (Accessed: 18 August 2016).

[8]- NHS Direct Wales website [no date]. (Online). Available at: http://www.nhsdirect.wales.nhs.uk/aboutus/whatisnhsdirectwales (Accessed: 18 August 2016).

[9]- NHS 24 website [no date]. [Online]. Available at: http://www.nhs24.com (Accessed 18 August 2016). 
[10]- Department of Health. 2015. NHS Reference Costs. [Online] Available at: https://www.gov.uk/government/collections/nhs-reference-costs (Accessed: 23 June 2016).

[11]- Department of Health. 2015. Reference Cost Collection: National Schedule of Reference Costs - Year 2014 - 15 [Online]. Available at: https://www.gov.uk/government/uploads/system/uploads/attachment_data/file/480791/20 14-15_National_Schedules.xlsx (Accessed: 23 June 2016).

[12]- Bateman DN, Carroll R, Pettie J, Yamamoto T, Elamin ME, Peart L, Dow M, Coyle J, Cranfield KR, Hook C, Sandilands EA, Veiraiah A, Webb D, Gray A, Dargan PI, Wood DM, Thomas SH, Dear JW, Eddleston M. 2014. Effect of the UK's revised paracetamol poisoning management guidelines on admissions, adverse reactions and costs of treatment. Br J Clin Pharmacol (78); 610-618.

[13]- McQuade DJ, Dargan PI, Keep J, Wood DM. 2012. Paracetamol toxicity: what would be the implications of a change in UK treatment guidelines? Eur J Clin Pharmacol (68): $1541-1547$. 
[14]- Personal Social Services Research Unit. Unit Costs of Health and Social Care.2015.

[Online] Available at: http://www.pssru.ac.uk/project-pages/unit-

costs/2015/index.php?file=community-based-health-care-staff (Accessed: 27 June 2016).

[15]- IPCS/EAPCCT. Poisoning Severity Score (PSS). [Online]. Available at:

http://www.who.int/ipcs/poisons/pss.pdf (Accessed: 8 August 2017).

[16]- Blizzard JC, Michels JE, Richardson WH, Reeder CE, Schulz RM, Holstege CP. 2008. Cost-benefit analysis of a regional poison center. Clin Toxicol (Phila)46 (5): 450456.

[17]- The Lewin Group Inc. 2012. Final Report on the Value of the Poison Center System. [Online] Available at:

https://aapcc.s3.amazonaws.com/files/library/Value_of_the_Poison_Center_System_FIN AL_9_26_2012_--_FINAL_FINAL_FINAL.pdf (accessed: 31st March 2016).

[18]- Miller TR, Lestina DC. 1997. Costs of poisoning in the United States and savings from poison control centers: a benefit-cost analysis. Ann Emerg Med (29) 2:239-245. 
[19]- Ponampalam R, Loh CS. 2010. Cost Benefits of the Drug and Poison Information Centre in Preventing Unnecessary Hospitalisation: the Singapore Experience. Hong Kong Journal of Emergency Medicine; 17 (1) 45-53.

[20]- Zaloshnja E, Miller T, Jones P, Litovitz T, Coben J, Steiner C, Sheppard M. 2008. The impact of poison control centers on poisoning-related visits to EDs--United States, 2003. Am J Emerg Med 26 (3):310-315.

[21]- Zaloshnja E, Miller T, Jones P, Litovitz T, Coben J, Steiner C, Sheppard M. 2006. The potential impact of poison control centers on rural hospitalization rates for poisoning. Pediatrics 118(5):2094-100.

[22]- Tak CR, Malheiro MC, Bennett HK, Crouch BI. 2017. The value of a poison control center in preventing unnecessary ED visits and hospital charges: A multi-year analysis. Am J Emerg Med 35: 438-443.

[23]- Adams RD, Lupton D, Good AM, Bateman DN. 2009. UK childhood exposures to pesticides 2004-2007: a TOXBASE toxicovigilance study. Arch Dis Child 94:417-420. 
[24]- Perry L, Adams RD, Bennett AR, Lupton DJ, Jackson G, Good AM, Thomas SHL, Vale JA, Thompson JP, Bateman DN, Eddleston M. 2014. National toxicovigilance for pesticide exposures resulting in health care contact-An example from the UK's National Poisons Information Service. Clin Toxicol 52:5; 549-555. 
Table 1: Source of telephone enquiries:

\begin{tabular}{|l|c|}
\hline Source & Calls (n) \\
\hline NHS 111, NHS 24 or NHS Direct* & 1248 \\
\hline General Practitioner/Primary Care & 449 \\
\hline Ambulance & 226 \\
\hline HM Prison & 54 \\
\hline Walk in Centre & 14 \\
\hline Community Pharmacist & 12 \\
\hline Other & 7 \\
\hline Support Services & 5 \\
\hline Police & 4 \\
\hline School & 4 \\
\hline Dental Establishment & 2 \\
\hline Nursing/Care Home & 2 \\
\hline Veterinary Practice & 1 \\
\hline Total & $\mathbf{2 0 2 8}$ \\
\hline
\end{tabular}

*Public health advice telephone services 
Table: 2 Changes to initial planned referrals following NPIS telephone advice:

\begin{tabular}{|c|c|c|c|c|c|}
\hline & \multirow{2}{*}{$\begin{array}{c}\text { Initial planned } \\
\text { referrals }\end{array}$} & \multicolumn{4}{|c|}{ Referrals following NPIS telephone consultation } \\
\hline & & $\begin{array}{c}\text { Emergency } \\
\text { Department }\end{array}$ & $\begin{array}{c}\text { General } \\
\text { Practitioner }\end{array}$ & Pharmacy & Home care \\
\hline $\begin{array}{l}\text { Emergency } \\
\text { Department }\end{array}$ & $1178(58.1 \%)$ & $\begin{array}{c}640 \\
(31.6 \%)\end{array}$ & $\begin{array}{c}74 \\
(3.6 \%)\end{array}$ & $\begin{array}{c}2 \\
(0.2 \%)\end{array}$ & $\begin{array}{c}462 \\
(22.8 \%)\end{array}$ \\
\hline $\begin{array}{c}\text { General } \\
\text { Practitioner }\end{array}$ & $515(25.4 \%)$ & $\begin{array}{c}119 \\
(5.9 \%)\end{array}$ & $\begin{array}{c}114 \\
(5.6 \%)\end{array}$ & $\begin{array}{c}1 \\
(0.05 \%)\end{array}$ & $\begin{array}{c}281 \\
(13.9 \%)\end{array}$ \\
\hline Pharmacy & $59(2.9 \%)$ & $\begin{array}{c}5 \\
(0.2 \%) \\
\end{array}$ & $\begin{array}{c}5 \\
(0.2 \%) \\
\end{array}$ & $\begin{array}{c}3 \\
(0.15 \%)\end{array}$ & $\begin{array}{c}46 \\
(2.3 \%)\end{array}$ \\
\hline Home care & $276(13.6 \%)$ & $\begin{array}{c}55 \\
(2.8 \%)\end{array}$ & $\begin{array}{c}12 \\
(0.6 \%)\end{array}$ & 0 & $\begin{array}{c}209 \\
(10.3 \%)\end{array}$ \\
\hline $\begin{array}{l}\text { Final number of } \\
\text { referrals }\end{array}$ & 2028 & $\begin{array}{c}819 \\
(40.4 \%)\end{array}$ & $\begin{array}{c}205 \\
(10.1 \%)\end{array}$ & $\begin{array}{c}6 \\
(0.3 \%)\end{array}$ & $\begin{array}{c}998 \\
(49.2 \%)\end{array}$ \\
\hline $\begin{array}{c}\text { Absolute } \\
\text { change (Cl) }\end{array}$ & & $\begin{array}{c}-17.7 \% \\
(14.6,20.7)\end{array}$ & $\begin{array}{c}-15.3 \% \\
(12.9,17.6)\end{array}$ & $\begin{array}{c}-2.6 \% \\
(1.8,3.5)\end{array}$ & $\begin{array}{c}+35.6 \% \\
(32.9,38.2)\end{array}$ \\
\hline P value* & & $<0.0001$ & $<0.0001$ & $<0.0001$ & $<0.0001$ \\
\hline
\end{tabular}

*Chi-square test with Yates continuity correction. 
Table: 3 Analysis of telephone enquiry data according to time received and PSS. Note that negative value reflects increased ED referrals following NPIS telephone consultation.

\begin{tabular}{|c|c|c|c|c|c|c|c|}
\hline & $\frac{\text { Surveyed calls }}{\text { (n) }}$ & $\frac{\text { ED referrals }}{\text { avoided }(\mathrm{n})}$ & $\underline{\%}$ & $\frac{\text { Annual calls }}{(\mathrm{n})}$ & $\begin{array}{l}\frac{\text { Annual ED }}{\text { referrals }} \\
\text { avoided (n) }\end{array}$ & \multicolumn{2}{|c|}{ Savings (f) } \\
\hline $\begin{array}{l}\text { (a) PSS } 0 \text { or unclassified, } \\
\text { office hours }\end{array}$ & 796 & 189 & $23.7 \%$ & 11080 & 2626 & $f$ & 411,337 \\
\hline $\begin{array}{l}\text { (b) PSS O or unclassified, } \\
\text { out of hours }\end{array}$ & 797 & 141 & $17.7 \%$ & 14827 & 2624 & $f$ & 411,023 \\
\hline (c) PSS $\geq 1$, office hours & 238 & 33 & $13.9 \%$ & 3463 & 481 & $f$ & 75,344 \\
\hline (d) PSS $\geq 1$, out of hours & 197 & -4 & $-2.0 \%$ & 4489 & -90 & $-f$ & 14,098 \\
\hline Totals* & 2028 & 359 & $17.7 \%$ & 33859 & 5641 & $f$ & 883,606 \\
\hline Overall** & 2028 & 359 & $17.7 \%$ & 33859 & 5994 & $f$ & 938,900 \\
\hline
\end{tabular}

* Totals of groups A to D when calculated separately.

** Overall surveyed calls and ED referrals avoided prior to correction as per PSS/time of call (*). 
Table: 4 Changes to initial planned referrals following TOXBASE ${ }^{\circledR}$ consultation:

\begin{tabular}{|c|c|c|c|c|c|}
\hline & \multirow{2}{*}{$\begin{array}{c}\text { Initial planned } \\
\text { referrals }\end{array}$} & \multicolumn{3}{|c|}{ Referrals following TOXBASE ${ }^{\circledR}$ consultation } \\
\cline { 3 - 6 } & $\begin{array}{c}\text { Emergency } \\
\text { Department }\end{array}$ & $\begin{array}{c}\text { General } \\
\text { Practitioner }\end{array}$ & Pharmacy & Home care \\
\hline $\begin{array}{c}\text { Emergency } \\
\text { Department }\end{array}$ & $410(48.2 \%)$ & $\begin{array}{c}310 \\
(36.4 \%)\end{array}$ & $\begin{array}{c}31 \\
(3.6 \%)\end{array}$ & $\begin{array}{c}5 \\
(0.6 \%)\end{array}$ & $\begin{array}{c}64 \\
(7.5 \%)\end{array}$ \\
\hline $\begin{array}{c}\text { General } \\
\text { Practitioner }\end{array}$ & $175(20.6 \%)$ & 19 & 115 & 0 & 41 \\
& & $(2.2 \%)$ & $(13.5 \%)$ & & $(4.8 \%)$ \\
\hline Pharmacy & $19(2.2 \%)$ & 3 & 2 & 6 & 8 \\
\hline Home care & $247(29 \%)$ & $(0.4 \%)$ & $(0.2 \%)$ & $(0.7 \%)$ & $(0.9 \%)$ \\
\hline $\begin{array}{c}\text { Final number of } \\
\text { referrals }\end{array}$ & 851 & $(1 \%)$ & $(1.4 \%)$ & $(0.2 \%)$ & 224 \\
\hline $\begin{array}{c}\text { Absolute } \\
\text { change (CI) }\end{array}$ & & 341 & 160 & 13 & 337 \\
\hline P value* & & $(40 \%)$ & $(18.8 \%)$ & $(1.5 \%)$ & $(39.6 \%)$ \\
\hline
\end{tabular}

*Chi-square test with Yates continuity correction. 


\section{Supplementary material: Telephone survey script and TOXBASE pop-up questions}

\section{(A) NPIS Telephone survey script for primary care enquirers}

Thank you for calling the NPIS.

We are currently running a service evaluation of the NPIS advisory service.

This consists of only two short questions; one at the beginning and one at the end of this consultation.

Would you be happy to participate?

If yes, then present the following question:

1- If the NPIS telephone advice service was unavailable which of the following options would best represent your management of the case you are calling about?

- Attend a hospital emergency department XX1A

- Attend/follow up at a GP surgery XX1B

- Attend a pharmacy XX1C

- Home care/no treatment XX1D

Next question following advice:

2- $\quad$ Following the telephone advice received from the NPIS which of the following options would best represent your planned management now:

- Attend a hospital emergency department XX2A

- Attend/follow up at a GP surgery XX2B

- Attend a pharmacy XX2C

- Home care/no treatment XX2D

Thank you for your kind cooperation.

TOXBASE survey

(b) Questions were presented to registered primary care users via pop up box on TOXBASE:

Before you read TOXBASE, please tell us how you would manage your patient?

Options

- Attend a hospital emergency department

- Attend/follow up at a GP surgery

- Attend a pharmacy 
- Home care/no treatment

After reading TOXBASE, please tell us how you will now manage your patient?

Options

- Attend a hospital emergency department

- Attend/follow up at a GP surgery

- Attend a pharmacy

- Home care/no treatment 